\title{
JOGOS EDUCATIVOS NO DESENVOLVIMENTO DO APRENDIZADO
}

Maria das Dores Soares Silva ${ }^{1}$

Cleidejane Soares de Barros ${ }^{2}$

Betijane Soares de Barros ${ }^{3}$

Ivaci Bonfim Pinheiro ${ }^{4}$

Ivaldo Sales Nascimento Júnior 5

Maria Suely Cruz Agra ${ }^{6}$

\section{RESUMO}

O lúdico apresenta-se como instrumento transformador das práticas pedagógicas e como forte aliada no desenvolvimento do processo ensino-aprendizagem. Considerou produções científicas publicadas entre 2017 a 2020, nos seguintes sites: BVS e Scielo. E, tem por objetivo analisar a influência da ludicidade como instrumento facilitador para ensino-aprendizagem. Tendo utilizado como metodologia a revisão bibliográfica. Deste modo, a atividade lúdica, com todas as suas nuances, contribui significativamente para o processo educacional, sendo um instrumento facilitador da aprendizagem.

PALAVRAS-CHAVE: Atividade lúdica. Processo educacional. Ensino-aprendizagem.

\footnotetext{
1 mdss@hotmail.com

2 dr.csbarros@hotmail.com

3 bj-sb@hotmail.com

4 ivaci18@outlook.com

5 ivaldosalesjunior@bol.com.br

6 mariasuely@sefaz.al.gov.br
} 


\section{INTRODUÇÃO}

$\mathrm{Na}$ construção dos complexos saberes típicos do ambiente escolar, o conjunto de conhecimentos alcançados por meio do lúdico era incompatível, pois o aprender demanda concentração e não combinava com brincar, rir e se divertir, considerados distração. Com o passar do tempo, o lúdico, o brincar passou a estar presente na vida social e cultural das pessoas. Apenas, atualmente, as atividades lúdicas passaram a ser consideradas como fator importante para o ensinoaprendizagem nas instituições escolares. A atividade lúdica apresenta-se como instrumento transformador das práticas pedagógicas e como forte aliada no desenvolvimento processo ensinoaprendizagem da criança e adolescente (QUIXADÁ, 2018).

O processo educacional é efetivado respeitando vários fatores, como a idade do aluno, a prática pedagógica, entre outros, mas para que a aprendizagem de fato aconteça de forma eficiente é necessário entusiasmo. Assim, as práticas pedagógicas devem ser embasadas na dinamicidade através de atividades que proporcionem prazer e despertem o interesse (SOUSA et. al., 2018).

A atividade lúdica apresenta-se como resposta a essa dinamicidade da prática pedagógica e se destaca pela importância que tem para o desenvolvimento intelectual da criança e do adolescente, através de jogos e brincadeiras lúdicas com fim educativo, tendo no professor o mediador para fazer o lúdico acontecer da maneira correta a proporcionar o aprendizado (CORSI, 2018).

A cultura lúdica proporciona referências que admitem a interpretação de jogos como atividades lúdicas e demonstram o potencial que os jogos e a recreação lúdica possuem dentro do processo educacional (MINEIRO, 2019).

\section{METODOLOGIA}

O método utilizado para elaboração da pesquisa foi a revisão bibliográfica não sistemática, obedecendo alguns critérios como a exposição de do tema, objetivos e dados lógicos para pesquisa, como sites e biblioteca acessados.

\section{Os Jogos Educativos Para Desenvolvimento Do Aprendizado}

$\mathrm{Na}$ construção dos complexos saberes típicos do ambiente escolar, o conjunto de conhecimentos alcançados por meio do lúdico era incompatível, pois o aprender demanda concentração e não combinava com brincar, rir e se divertir, considerados distração. Com o passar do tempo, o lúdico, o brincar passou a estar presente na vida social e cultural das pessoas. Apenas atualmente, as atividades 
lúdicas passaram a ser considerados como fator importante para o ensinoaprendizagem nas instituições escolares (JURDI, 2018).

Os jogos e brincadeiras educativas proporcionam aos alunos um ambiente agradável e motivador, em todo o ambiente escolar, e são necessários para que o professor possa conhecer e desenvolver o conhecimento dos sentimentos próprios e de ações que colaborem com os fatores sociais e culturais (SOUSA, 2018).

Diante das dificuldades vivenciadas pelos professores em sala de aula, em especial nas séries iniciais, em relação ao ensinoaprendizagem, percebeu-se a necessidade de procurar formas de aperfeiçoar suas práticas pedagógicas por meios de metodologia e estratégias diferentes que despertem nos alunos o gosto de estudar, assim, a atividade lúdica surgiu como um instrumento importante para trazer dinâmica para a sala de aula (COLLA, 2019).

\section{Os jogos educativos e a recreação lúdica no desenvolvimento do aprendizado}

Os jogos educativos proporcionam um conjunto de condiçõos especiais para a aprendizagem das crianças e jovens de todas as faixas etárias. Para que os jogos possam desempenhar a função de facilitador da aprendizagem, de modo significativo dentro da sala de aula, deve ser aplicado de maneira correta com objetivos definidos que se deseja alcançar, e para tanto a figura do professor possui fundamental importância na aplicação das atividades lúdicas (CORSI, 2018).

$\mathrm{O}$ docente tem a incumbência de expor o objetivo que se deseja alcançar com a utilização do jogo, bem como, de ser o responsável pela organização e auxílio da atividade, direcionando os alunos para o aprendizado através do ato de participar e interagir no jogo (QUIXADÁ, 2018).

Quando os docentes se propõem a utilizar atividades lúdicas educativas em seu trabalho, ele terá um grande desafio a transpor, pois é sua reponsabilidade exercer o papel de mediador e, se for preciso, jogar e brincar com seus alunos, além de verificar atentamente e explicar como estão acontecendo às interações e troca dos saberes. Aos docentes caberá o papel de propiciar situações estimuladoras e que produzam os efeitos necessários para a aprendizagem (PEREIRA, 2017).

A importância dos jogos dentro processo educacional e demais atividades recreativas lúdicas perpassa o aprendizado do aluno, porquanto proporciona ao professor um feedback de sua prática pedagógica podendo, a partir daí, aperfeiçoar sua práxis educacional (JURDI, 2018). 
É evidente a contribuição do jogo para o aprendizado significativo. O jogo é um instrumento que, também, pode ser utilizado como material didático e como instrumento de avalição da aprendizagem dos alunos. A aprendizagem significativa ocorrerá quando aluno puder relacionar conceitos anteriores com novos conceitos, por isso a tamanha importância do papel do professor como facilitador, como mediador, na utilização de jogos (MINEIRO 2019).

Os jogos tem apresentado várias utilidades dentro processo educativo, não se resumindo apenas a memorização do conteúdo dado, tem objetivado estimular o raciocínio, a participação ativa e a reflexão, e com isso, construir e reconstruir conhecimentos (SOUSA, 2018).

O jogo oportuniza a criança aprender brincando. Essa é uma característica universal de todas as crianças e são elas próprias mediados pelos educadores que conduzem seu próprio aprendizado (JURDI, 2018).

As atividades lúdicas preparam a criança para a vida, para compreender e suportar também as fatalidades tendo um valor significativo no desenvolvimento psíquico, realizando atos, experimentando situações e adquirindo experiências que não poderiam ser vivenciadas, assim o lúdico possui funções específicas para o ser humano (COLLA, 2019).
O sentido lúdico de cada brincadeira varia de acordo com a idade da criança, e é o dia a dia da criança que vai dar a origem a imaginação, sendo a brincadeira uma representação do mundo real. A criança descobre no brincar de faz de conta, numa leitura narrativa ou jogos simbólicos, o universo das relações sociais, interpessoais e do indivíduo com os objetos (MINEIRO, 2019).

No contexto escolar, os jogos e brincadeiras vêm evidenciar e compreender a importância de organizar diferentes agrupamentos em sala de aula, adequando às técnicas de acordo com a turma para que sejam alcançardos os objetivos almejados nas diferentes áreas do conhecimento e, assim, a aprendizagem aconteça de forma abrangente (PEREIRA, 2017).

Deste modo, os jogos educativos e brincadeiras lúdicas são instrumentos importantes no processo educacional, funcionam como facilitadores da aprendizagem por proporcionarem prazer e diversão aliados ao conteúdo trabalhado, tenso o professor um papel essencial no planejamento, execução e desempenho do jogo/brincadeira (COLLA, 2019).

\section{CONCLUSÃO}

No decorrer do presente trabalho, observamos que a ludicidade proporciona um experimentar que torna a aprendizagem prazerosa, interessante e que causa 
entusiasmo. O lúdico proporciona um desenvolvimento sadio e harmonioso, sendo uma tendência instintiva da criança. Ao brincar, a criança aumenta a independência, estimula sua sensibilidade visual e auditiva, valoriza a cultura popular, desenvolve habilidades motoras, diminui a agressividade, exercita a imaginação e a criatividade, aprimora a inteligência emocional, aumenta a integração, promovendo, assim, o desenvolvimento sadio, o crescimento mental e a adaptação social.

A atividade lúdica é aquela atividade que envolve entretenimento, proporciona prazer e está relacionada ao ato de brincar. A atividade lúdica é um instrumento facilitador para o ensinoaprendizagem, no qual há uma relação entre professor-aluno e aluno-aluno, fazendo com que sujeitos envolvimentos do processo educacional interajam, socialize e desenvolva habilidades.

Os jogos educativos contribuem não só para a apreensão dos conteúdos expostos em sala de aula de forma eficiente, mas, contribui também, para estimular o raciocínio, proporcionar uma participação ativa e a reflexão, construindo e reconstruindo conhecimentos, e vai além, podendo ser utilizado como forma de avaliação no ensino-aprendizagem.

Portanto, cabe à escola e a nós, educadores, recuperarmos a ludicidade infantil de nossos alunos, ajudando-os a encontrar um sentido para suas vidas. Ao brincar, não se aprendem somente conteúdos escolares; aprende-se algo sobre a vida e a constante peleja que nela travamos.

\section{REFERÊNCIAS}

COLLA, Rodrigo Ávila. O brincar e o Cuidado nos Espaços da Educação Infantil: desenvolvendo os animais que somos. Rev. Bras. Estud. Pedagog., v. 100, n. 254, p. 111126, Brasília, jan./abr. 2019.

CORSI, Laís Marconato; MARCO, Ademir de; ONTAÑÓN, Teresa. Educação Física na Educação Infantil: proposta interdisciplinar de atividades circenses. Pensar a Prática, v. 21, n. 4, Goiânia, out./dez. 2018.

JURDI, Andrea Perosa Saigh; SILVA, Carla Cilene Baptista; LIBERMAN, Flavia. Inventários das Brincadeiras e do Brincar: ativando uma memória dos afetos.

Comunicação Saúde Educação, 22(65):6038, 2018.

MINEIRO, Márcia; D’ÁVILA, Cristina. Ludicidade: compreensões conceituais de pósgraduandos em educação. Educ. Pesqui., São Paulo, v. 45, 2019.

PEREIRA, Íris Susana Pires. O Princípio de Prática Situada na Aprendizagem da Literacia: a perspectiva dos alunos. Educ. Pesqui., v. 43, n. 2, p. 393-410, São Paulo, abr./jun., 2017.

QUIXADÁ, Luciana Martins; LINS, Sylvie Ghislaine Delacours Soares; TAVARES, Ana Carolina Pontes. O Lúdico como Atividade Discursiva e como uma Via para a Formação do Leitor: teoria e relato de pesquisa em uma escola pública em Fortaleza-CE. Educação \& Formação, v. 3, n. 7, p. 182-199, Fortaleza, jan./abr. 2018. 
SOUSA, Laísa Cristina Martins de; LOJA,

Luiz Fernando Batista; PIRES, Diego Arantes

Teixeira. Bingo periódico: atividade lúdica no ensino de tabela periódica. Revista Thema, V. $15, n^{\circ} 04,2018$. 
Rev. Científica Evidência, Maceió, v. 6, n.1, p. 01-20, abr/jun, 2021

Melo. et-al. 